\title{
CARACTERIZAÇÃO GENÉTICA DE ESPÉCIES DE Passiflora POR MARCADORES MOLECULARES ANÁLOGOS A GENES DE RESISTÊNCIA ${ }^{1}$
}

\author{
MARIANA DA SILVA PAULA², MARIA ESTHER DE NORONHA FONSECA ${ }^{3}$, \\ LEONARDO SILVA BOITEUX ${ }^{3}$, JOSÉ RICARDO PEIXOTO ${ }^{4}$
}

RESUMO-O cultivo comercial do maracujá é afetado por diversos problemas fitossanitários, os quais contribuem para quebras de produção e significativa redução da vida útil dos plantios. Em algumas situações, a incidência de doenças pode inviabilizar o cultivo do maracujá. Fontes de resistência a distintas doenças têm sido identificadas em acessos de espécies de Passiflora. Neste trabalho, buscou-se avaliar a diversidade genética de acessos de oito espécies silvestres ( $P$. setacea, $P$. nitida, $P$. serratodigitata, $P$. caerulea, $P$. gibertii, $P$. odontophyla, $P$. edulis e $P$. coccinea) e de um híbrido interespecífico ( $P$. setacea $x$ P. coccinea), utilizando marcadores moleculares análogos a genes de resistência (RGAs). Verificou-se uma grande diversidade no perfil eletroforético de RGAs nos acessos de Passiflora, permitindo a anotação de 96 amplicons polimórficos entre, pelo menos, um par de acessos. Os níveis de dissimilaridade genética (calculados exclusivamente com os marcadores RGAs) variaram entre 0,40 e 0,89 nos acessos das espécies de Passiflora avaliadas. A análise de sequência de um subgrupo destes amplicons obtidos com primers RGAs indicou que estas bandas correspondem a regiões genômicas que contêm segmentos (motivos) com identidade aos encontrados em genes de resistência previamente caracterizados em outras espécies vegetais. Desta forma, os dados indicam a existência de um repertório variado de marcadores do tipo RGA em Passiflora que podem ser potencialmente úteis em sistemas de caracterização molecular de germoplasma e em programas de melhoramento genético visando à resistência a doenças nesta cultura.

Termos para indexação: Passiflora, marcadores moleculares, RGAs, polimorfismo.

\section{GENETIC CHARACTERIZATION OF Passiflora SPECIES BY ANALOG MARKERS OF RESISTANCE GENES}

\begin{abstract}
The commercial cultivation of passion fruit can be affected by many diseases, which might induce sever fruit yield losses and significant life cycle reduction of the crop. In some situations disease incidence can make the passion fruit production not economically viable. Sources of resistance against several pathogens have been identified in accessions of Passiflora germplasm. In the present research we evaluate by using RGAs ("analogs markers of resistance gene") the genetic diversity of accessions belonging to eight wild species (P. setacea, P. nitida, P. serratodigitata, $P$. caerulea, $P$. gibertii, $P$. odontophyla, P. eduli, and $P$. coccinea) as well as one interspecific hybrid ( $P$. setacea. $x$ P. coccinea). A remarkable diversity was observed among the RGA eletrophoretic profiles of the accessions, allowing the annotation of 96 polymorphic amplicons able to discriminate at least one pair of accessions. The levels of genetic dissimilarity in this group of Passiflora accessions (using exclusively this collection of RGA markers) ranged from 0.40 to 0.89 . The sequence analysis of a subgroup of RGA amplicons indicated that they correspond to genomic regions that encompass typical disease resistance gene motifs described in other plant species. Our results indicate a quite variable structural repertoire of RGA segments in Passiflora species with many of them being potentially useful as molecular markers for germplasm fingerprinting systems and also for assisted selection strategies in disease resistance breeding programs in this crop.
\end{abstract}

Index terms- Passiflora, molecular markers, RGAs, polymorphic.

\footnotetext{
'(Trabalho 039-09). Recebido em: 05-02-2009. Aceito para publicação em: 23-10-2009.

${ }^{2}$ Eng. Agrônoma, Msc em Fitopatologia (UnB). marianaspaula@gmail.com. Suporte Financeiro: CNPQ.

${ }^{3}$ Embrapa Hortaliças, C. Postal 218, 70359-970 Brasília-DF. mesther@cnph.embrapa.br ; boiteux@cnph.embrapa.br

${ }_{4}^{4}$ Professor Doutor da Universidade de Brasília. C. Postal: 04508, 70910-900, Brasília-DF. peixoto@unb.br
} 


\section{INTRODUÇÃO}

No Brasil, as doenças e pragas são os principais fatores que ameaçam a expansão e a produtividade dos cultivos de maracujá (Junqueira et al., 2005). Doenças causadas por fungos afetam a planta de maracujá desde a fase de sementeira até a fase adulta, prejudicando raízes, caule, folhas, flores e frutos (Santos Filho \& Santos, 2003). A antracnose (causada pelo fungo Colletotrichum gloeosporioides) é considerada a principal doença de pós-colheita do maracujá, com impacto negativo no período de conservação dos frutos (Souza, 2005). Xanthomonas campestris pv. passiflorae (agente causal do cancrobacteriano) e Ralstonia solanacearum (agente da murcha e podridão de raízes) são as principais bactérias registradas causando danos na cultura do maracujazeiro (Santos \& Santos Filho, 2003). Entre os vírus que causam doenças no maracujazeiro, têm-se o CABMV (Cowpea aphid-borne mosaic virus), que causa o endurecimento dos frutos, e CMV (Cucumber mosaic virus), que causa mosaico, e PYMV (Passion fruit yellow mosaic virus), causador do mosaico-amarelo (Barbosa \& Santos Filho, 2003). As espécies de Meloidogyne e Rotylenchulus reniformis representam importantes agentes causais de perdas econômicas na cultura, resultando na limitação de produção dos frutos e na redução na longevidade da planta (Sharma et al., 2004).

Fontes de resistência a estes patógenos e doenças têm sido identificadas em germoplasma de espécies cultivadas e selvagens de Passiflora. Acessos com resistência a distintas doenças têm sido registrados nas espécies $P$. nitida, $P$. caerulea, P. laurifolia, P. suberosa, P. alata, P. coccinea, $P$. gibertii e $P$. setacea. De acordo com estudo de Paula (2006), $P$. setacea mostrou-se resistente à $M$. incognita. Acessos de $P$. nitida mostraram-se resistentes à antracnose (C. gloeosporioides), e acessos de $P$. caerulea apresentaram resistência à $X$. axonopodis pv. passiflorae (Menezes et al., 1994; Oliveira et al., 1994; Meletti \& Bruckner, 2001; Fischer, 2003).

Os genes de resistência, caracterizados até o presente momento em plantas, possuem regiões filogeneticamente conservadas, denominadas "motivos", os quais podem incluir proteínas ricas em leucina (LRR), sítios de ligação a nucleotídeos (NBS), estruturas complexas de NBS-LRR e proteínas quinases (Staskawicz et al., 1995; Hammond-Kosack \& Jones, 1997). Esta conservação estrutural apresenta interesse do ponto de vista genético, uma vez que claramente sugere que essas regiões conservadas poderiam representar sítios de relevância biológica na expressão fenotípica dos genes de resistência (Bent, 1996). Desta forma, com base nessa conservação filogenética, foram desenvolvidos diversos primers degenerados com o objetivo de amplificar regiões análogas a genes de resistência (RGAs) em várias espécies vegetais usando técnicas simplificadas de PCR ("polymerase chain reaction") heterólogo (Leister et al., 1996; Kanazin et al., 1996; Yu et al., 1996). Em diversos trabalhos, foi observado que os marcadores do tipo RGAs são fortemente ligados a genes de resistência ou podem mesmo representar segmentos de genes de resistência funcionais (Hammond-Kosack \& Jones, 1997; Collins et al., 2001). Neste sentido, os marcadores RGA podem constituir uma ferramenta muito útil para a construção de mapas genéticos e em seleção assistida dentro de programas de melhoramento genético vegetal. A possibilidade de gerar um grande número de polimorfismos entre diferentes acessos de uma mesma espécie ou gênero também pode permitir o uso dos marcadores RGA em sistemas de caracterização genética de acessos e cultivares (Hammond-Kosack \& Jones, 1997). No entanto, até o presente momento, não existem relatos na literatura sobre a identificação e utilização desta classe de marcadores para o gênero Passiflora.

Considerando que fenótipos de resistência são, muitas vezes, de difícil identificação, os marcadores moleculares RGA podem representar uma importante ferramenta para a seleção de genótipos de interesse e na identificação de genes de resistência em plantas (Tullu et al., 2006; Geffroy et al., 1999). Neste contexto, o presente trabalho buscou avaliar possibilidade de gerar (via PCR heterólogo) marcadores do tipo RGA usando como molde DNA extraído de acessos de oito espécies silvestres e de um híbrido interespecífico de Passiflora. Considerando que não existem relatos de clonagem e/ou isolamento de genes de resistência para o gênero Passiflora, o presente trabalho teve os seguintes objetivos: (1) avaliar a utilidade de uma coleção de primers degenerados do tipo RGA em gerar polimorfismos entre acessos de Passiflora; (2) avaliar a potencial utilização de marcadores moleculares do tipo RGA em estudos de diversidade genética no gênero Passiflora; e (3) caracterizar, através de clonagem e sequenciamento, alguns dos amplicons do tipo RGA presentes em diferentes acessos de espécies de Passiflora.

\section{MATERIAL E MÉTODOS}

O presente trabalho foi realizado no laboratório de Melhoramento Genético e Análise Genômica da Embrapa Hortaliças, Brasília-DF, durante o período de novembro de 2005 a março de 2006. 
Folhas jovens foram coletadas de acessos de oito espécies ( $P$. setacea, $P$. nitida, $P$. serratodigitata, $P$. caerulea, $P$. gibertii, $P$. odontophyla, $P$. edulis nativo e $P$. coccinea) e de um híbrido interespecífico ( $P$. setacea $x$ P. coccinea), oriundo do banco de germoplasma da Embrapa Cerrados (CPAC). As amostras foram utilizadas no processo de extração de DNA utilizando o método de CTAB 2X (que utiliza solventes orgânicos, tais como álcool isoamílico e clorofórmio), essencialmente como descrito por Saghai-Marrof et al. (1984) modificado por Boiteux et al. (1999). Para a obtenção de marcadores do tipo RGAs, foi utilizada uma estratégia de amplificação via PCR heterólogo, com seis combinações de iniciadores de transcrição (primers) descritos na literatura (S2+As1, S2+As2, $\mathrm{S} 2+\mathrm{As} 3, \mathrm{~S} 2+\mathrm{LM} 637, \mathrm{~F} 1+\mathrm{As} 2$ e S2+R1). Esses pares de primers degenerados foram desenhados para anelar com o motivo NBS ("Nucleotide Binding Site") presentes várias classes de genes de resistência a doenças (Leister et al., 1996; Pan et al., 2000). Para a amplificação seletiva de marcadores RGA foi utilizado um volume de reação de $25 \mu \mathrm{L}$ contendo: $20 \mathrm{mM}$ Tris- $\mathrm{HCl}(\mathrm{pH} 8,4), 50 \mathrm{mM} \mathrm{KCL}, 1,2 \mathrm{mM}$ de $\mathrm{MgCl}_{2}$ $(50 \mathrm{mM}) ; 2 \mathrm{mM}$ de cada deoxinucleotídeo trifosfato (dNTPs), 20ng de DNA genômico, 0,2 unidades da enzima Taq polimerase (Invitrogen) e $1,2 \mu \mathrm{M}$ de cada primer. As amplificações foram realizadas em placas de 96 poços em um termociclador (GeneAmp® PCR System 9700), programado para um ciclo de 5 minutos a $95^{\circ} \mathrm{C}$, seguido de 35 ciclos repetidos de 30 segundos a $95^{\circ} \mathrm{C}$ (desnaturação), 1 minuto a $37^{\circ} \mathrm{C}$ (anelamento) com um "ramp" de 70\% (ou seja, a velocidade de aumento de temperatura foi apenas $70 \%$ da velocidade máxima do aparelho, permitindo um anelamento gradual dos primers com o DNA molde) e 5 minutos a $72^{\circ} \mathrm{C}$ (extensão) e extensão final de 10 minutos a $72^{\circ} \mathrm{C}$. Os produtos das reações de amplificação foram separados por eletroforese em gel de agarose na concentração de 1,2\% em tampão de TAE $1 \mathrm{X}$, corados com brometo de etídeo $(10 \mathrm{mg} / \mathrm{mL})$ e fotografados sob luz ultravioleta $(302 \mathrm{~nm})$ em sistema de vídeo EagleEye $^{\mathrm{TM}}$ (Stratagene $\left.{ }^{\circledR}\right)$.

Os polimorfismos observados para marcadores do tipo RGA foram convertidos em matriz de dados binários (presença e ausência de cada banda/ amplicon), a partir da qual foram estimadas as distâncias genéticas entre os diferentes acessos, com base no complemento do coeficiente de similaridade de Nei \& Li como descrito no Programa Genes (Cruz, 1997). A matriz de distâncias genéticas foi utilizada para realizar a análise de agrupamento, com o auxílio do Programa Statistic (Statsoft Inc., 1999). Como critério de agrupamento, foi empregado o método UPGMA. Com base na análise de agrupamento, diferentes gru- pos de similaridade foram definidos de acordo com os resultados do perfil de amplicon obtidos com DNA extraído de acessos de oito espécies silvestres e de um acesso de um híbrido interespecífico de Passiflora. Após a visualização e anotação dos amplicons com o auxílio do sistema de vídeo EagleEye ${ }^{\circledR}$, foi feita a purificação de DNA de alguns desses fragmentos. Estes segmentos de DNA genômico de um subconjunto de acessos de Passiflora foram removidos dos géis de agarose e clonados em um vetor bacteriano (plasmídeo pGEM $^{\circledR}$-T / Invitrogen). Foi feita a transformação em Escherichia coli, a qual é competente para captar o DNA exógeno de interesse (plasmídeo com inserto). Foi feita então multiplicação das bactérias transformadas (em meio LB; triptona, extrato de levedura e $\mathrm{NaCl}$ ) com o objetivo de obter quantidades suficientes de material de interesse, possibilitando, assim, o sequenciamento automático do DNA clonado. Após o sequenciamento foi feita a comparação entre as sequências obtidas de nucleotídeos usando o aplicativo LaserGene (DNAStar, Madison, Wisconsin, EUA). As sequências de DNA foram posteriormente convertidas em sequências proteicas e comparadas com as contidas no banco de genes NCBI (NCBI-National Center for Biotecnology Information, 2009).

\section{RESULTADOS E DISCUSSÃO}

Apenas os polimorfismos que foram constantes (estáveis) em três ou mais repetições das reações de PCR foram considerados para análise de dissimilaridade genética. Os pares de primers utilizados revelaram um total de 99 amplicons (sendo três deles monomórficos), ou seja, houve uma média de 16,5 amplicons para cada par de primers (Tabela 1). A dissimilaridade genética entre as espécies avaliadas variou entre 0,4 [entre a espécie $P$. setacea e o híbrido $\mathrm{F}_{1}(P$. coccinea $\times$ P. setacea $)$ ] e 0,889 [(entre $P$. gibertii e o híbrido $\mathrm{F}_{1}$ ( $P$. coccinea $\times$ P. setacea $\left.)\right]$ (Figura 1). Estes resultados indicam uma grande diversidade genética quanto aos marcadores do tipo RGAs entre os acessos das espécies avaliadas. Este é um indicativo do potencial que o sistema de marcadores RGA apresenta no sentido de gerar informações genéticas de interesse para uso em programas de melhoramento voltados para resistência a doenças. Este resultado está de acordo com outros trabalhos, tais como o de Mutlu et al. (2005), que mostraram a importância dos marcadores RGA para a caracterização de acessos de feijão (Phaseolus vulgaris L.). Da mesma forma, Valêncio (2005), a partir do estudo de caracterização de diferentes acessos de cebola, com utilização de marcadores RGA, pôde 
verificar a utilidade dessa técnica para trabalhos de mapeamento genético e caracterização de cultivares. Cantanhêde (2004) verificou a eficiência relativa da utilização de marcadores do tipo RGA em relação à técnica de RAPD, quanto à detecção de polimorfismos entre linhagens contrastantes para resposta a doenças causadas por Fusarium oxysporum f.sp. lycopersici raça 1 e espécies de Stemphylium em tomateiro. Tan et al. (2003) e Collins et al. (2001) também verificaram a importância da análise destes marcadores e sequenciamento de regiões conservadas NBS, o que auxilia na caracterização e manipulação de potenciais genes de resistência.

As sequências obtidas no presente trabalho apresentaram níveis de variáveis com sequências de proteínas relacionadas à resistência a doenças para diversas culturas (feijão, soja, cana-de-açúcar e outras), já contidas no banco de dados do NCBI, principalmente nas regiões NBS-LRR. A Figura 3 ilustra o alinhamento/comparação de três sequências obtidas usando DNA, molde extraído de acessos de $P$. setacea, $P$. serrato-digitata e $P$. nitida com um mRNA de uma proteína NBS-LRR, isolada em Populus trichocarpa. Embora Passiflora e Populus sejam filogeneticamente distintas, os níveis de identidade das sequências de Passiflora foram relativamente altos (entre $43,1 \%$ e $74 \%$ ) quando comparadas com uma sequência de $P$. trichocarpa (GeneBank XM 002297700).

Desta forma, os dados gerados a partir da utilização de marcadores do tipo RGA poderão ser valiosos para estudos mais detalhados de caracterização genética do maracujazeiro de forma a agregar informação quanto à obtenção de material resistente a doenças e para sistemas de caracterização de cultivares e organização de bancos de germoplasma. Para tal, será extremamente valioso o estabelecimento de um acervo mais completo das sequências polimórficas geradas neste trabalho, bem como validação destes marcadores em um número maior de genótipos de maracujá. Estudos adicionais, visando a identificar a associação de alguns destes marcadores com genes de resistência, poderão ser conduzidos envolvendo populações segregantes derivadas de cruzamentos entre alguns dos acessos avaliados.

TABELA 1 - Par de primers do tipo RGAs (análogos de genes de resistência) utilizados em sistema de PCR heterólogo visando a obter marcadores moleculares de nove genótipos de Passiflora spp. A tabela lista o código e a sequência dos primers e seus respectivos números de bandas polimórficas e monomórficas obtidas na análise utilizando DNA, molde extraído de nove genótipos de Passiflora.

\begin{tabular}{|c|c|c|c|}
\hline Primers & Sequência $5^{\prime}==>3^{\prime}$ & $\begin{array}{l}\mathrm{N}^{\circ} \text { de bandas } \\
\text { polimórficas }\end{array}$ & $\begin{array}{l}\mathrm{N}^{0} \text { de bandas } \\
\text { monomórficas }\end{array}$ \\
\hline $\mathrm{S} 2+\mathrm{As} 1$ & $\begin{array}{l}\text { GGIGGIGTIGGIAAIACIAC } \\
\text { CAACGCTAGTGGCAATCC }\end{array}$ & 20 & 0 \\
\hline $\mathrm{S} 2+\mathrm{As} 2$ & $\begin{array}{l}\text { GGIGGIGTIGGIAAIACIAC } \\
\text { IAAIGCIAGIGGIAAICC }\end{array}$ & 12 & 0 \\
\hline $\mathrm{S} 2+\mathrm{As} 3$ & $\begin{array}{l}\text { GGIGGIGTIGGIAAIACIAC } \\
\text { IAGIGCIAGIGGIAGICC }\end{array}$ & 9 & 1 \\
\hline S2 + LM 637 & $\begin{array}{l}\text { GGIGGIGTIGGIAAIACIAC } \\
\text { ARIGCTARIGGIARICC }\end{array}$ & 17 & 1 \\
\hline $\mathrm{F} 1+\mathrm{As} 2$ & $\begin{array}{l}\text { GGAATGGGIGGIGTIGGIAARAC } \\
\text { IAAIGCIIAGIGGIAAICC }\end{array}$ & 24 & 0 \\
\hline $\mathrm{S} 2+\mathrm{R} 1$ & $\begin{array}{c}\text { GGIGGIGTIGGIAAIACIAC } \\
\text { YCTAGTTGTRAYDATDAYYYTRC }\end{array}$ & 14 & 1 \\
\hline Total & & 96 & 3 \\
\hline
\end{tabular}




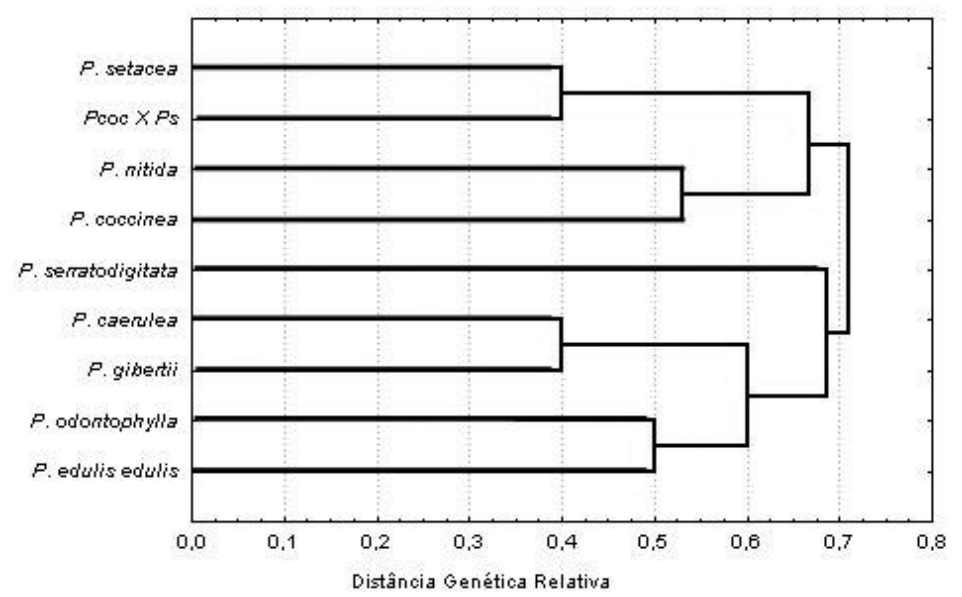

FIGURA 1 - Análise de agrupamento de nove acessos de Passiflora spp. com base na matriz de distâncias genéticas calculadas, utilizando-se de 96 marcadores moleculares (amplicons) gerados com uso dos pares de primers RGA listados na Tabela 1.
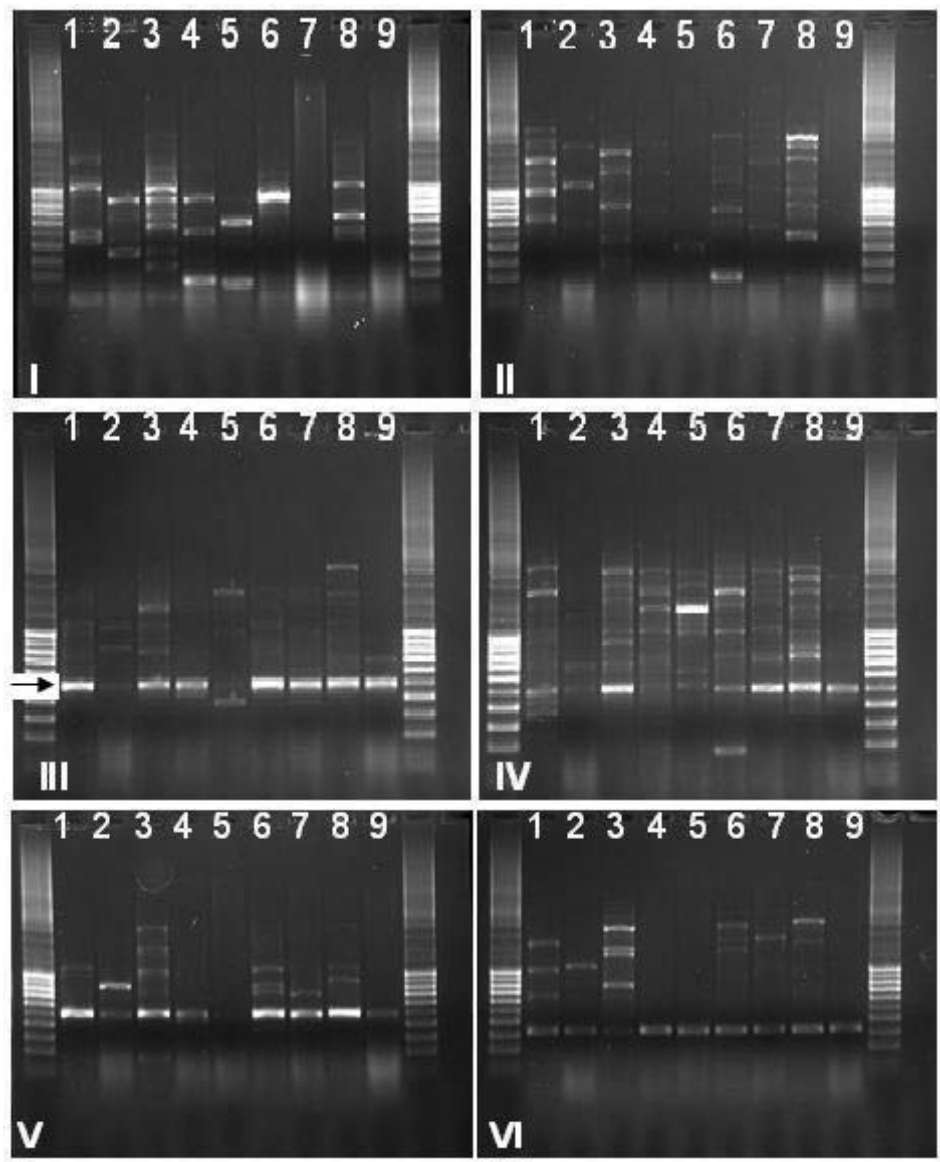

FIGURA 2 - Perfil eletroforéticos dos amplicons (marcadores) do tipo RGA gerados com um conjunto de seis combinações de primers degenerados, desenhados para anelar com regiões conservadas presentes em genes de resistência a doenças. Espécies de Passiflora avaliadas: (1) P. setacea; (2) P. nitida; (3) P. serratodigitata; (4) P. caerulea; (5) P. gibertii; (6) P. odontophylla; (7) $P$. edulis edulis nativo; (8) $P$. coccinea $x$ P. setacea F1, e (9) $P$. coccinea. Pares de primers utilizados: (I) S2/As1; (II) S2/As2; (III) S2/Lm637; (IV) F1/As2; (V) S2/As3, e (VI) S2/ R1. A seta no gel III indica os amplicons isolados do gel, clonados em vetor bacteriano e analisados via sequenciamento. 

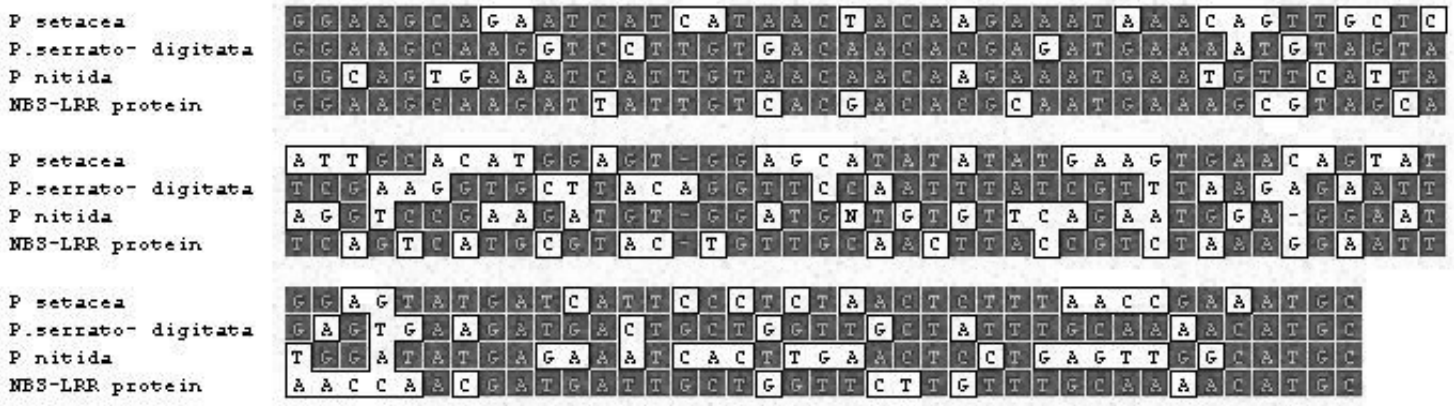

FIGURA 3 - Alinhamento dos produtos de sequenciamento de um subconjunto de amplicons obtidos a partir do par de 'primers' S2/LM637. O alinhamento foi obtido com o método Clustal, utilizando o programa Megalign (Lasergene, Madison-WI). Os amplicons foram comparados com a seqüência do mRNA que codifica uma proteína do tipo NBS-LRR de Populus trichocarpa (GeneBank XM 002297700 / Tuskan et al., 2006). A identidade de cada amplicon com o mRNA correspondente à proteína NBS-LRR é: Passiflora setacea $(43,1 \%)$, P. serrato-digitata (74\%) e P. nitida $(43,4 \%)$.

\section{CONCLUSÕES}

1-A partir de um sistema de PCR heterólogo, utilizando primers degenerados (obtidos a partir de informação de sequências de outras espécies vegetais), foi possível gerar um perfil do tipo RGA,também a partir de DNA genômico extraído de um grupo de acessos de espécies de Passiflora.

2-O sistema RGA foi eficiente em gerar amplicons polimórficos no grupo de acessos de Passiflora empregado no presente estudo e foi possível utilizar esta informação para estabelecer níveis de similaridade genética entre estes acessos.

3-Os amplicons sequenciados mostraram níveis de identidades com sequências relacionadas à resistência de plantas a doenças, contendo segmentos genômicos do tipo NBS-LRR (proteínas ricas em leucina e sítios de ligação a nucleotídeos).

\section{REFERÊNCIAS}

BARBOSA, C.J.; SANTOS-FILHO, H. P. Doenças causadas por vírus e similares. In: MARACUJÁ: fitossanidade. Brasília: Embrapa, 2003. (Frutos do Brasil)

BENT, A. F. Plant disease resistance genes: function meets structure. Plant Cell, Rockville, v.8, p. 17571771, 1996.
BOITEUX, L.S.; FONSECA, M.E.N.: SIMON, P.W. Effects of plant tissue and DNA purification method on RAPD-based genetic fingerprinting analysis in carrot (Daucus carota L.). Journal of American Society for Horticultural Science, Alexandria, v.124, p.32-38. 1999.

BRUCKNER, C. H. Perspectivas do melhoramento do maracujazeiro. In: MANICA, I. (Ed.). Maracujá: temas selecionados. Porto Alegre: Cinco Continentes, 1997. p.70.

CANTANHÊDE, I. S. L. Caracterização fenotípica, genética e molecular de genitores e populações segregantes e estimativas de parâmetros genéticos de atributos de interesse para melhoramento genético do tomateiro (Lycopersicon esculentum Mill.). 2004. 81 f. Dissertação (Mestrado) - Faculdade de Agronomia e Medicina Veterinária, Universidade de Brasília, Brasília, 2004.

COHN, E.; DUNCAN, L.W. Nematodes parasites of subtropical and tropical fruits trees. In: LUC, M.; SIKORA, R.A.; BRIDGE, J. (Ed.). Plant parasitic nematodes in subtropical and tropical agriculture. Wallingford: CAB International, 1990. p.347-362, 1990.

COLLINS, N.; PARK, R.; SPIELMEYER, W.; ELLIS, J.; PRYOR, A. J. Resistance gene analogs in barley and their relationship to rust resistance. Gene, Amsterdan, v.44, p.375-381, 2001. 
CRUZ, C. D. Programa GENES: Aplicativo computacional em estatística aplicada à genética (GENES - Software for Experimental Statistics in Genetics). Genetics and Molecular Biology, v.21, p.14154757, 1997.

FISCHER, I. H. Seleção de plantas resistentes e de fungicidas para o controle da "morte prematura" do maracujazeiro, causada por Nectria hematococca e Phytophthora parasítica. 2003. Dissertação (Mestrado) - Escola Superior de Agricultura "Luiz de Queiroz”, Universidade de São Paulo, Piracicaba, 2003.

GEFFROY, V.; SICARD, D.; OLIVEIRA, J.C.; SEVIGNAC, M.; COHEN, S.; GEPTS, P.; NEEMA, C.; LANGIN, T.; DRON, M. Identification of an ancestral resistance gene cluster involved in the coevolution process between Phaseolus vulgaris and its fungal pathogen Colletotrichum lindemuthianum. Molecular Plant-Microbe Interactions, St Paul, v.12, p.774-784, 1999.

HAMMOND-KOSACK, K. E.; JONES, J. D. G. Plant disease resistance genes. Annual Review of Plant Physiology and Plant Molecular Biology, Palo Alto, v.48, p. 575-607, 1997.

JUNQUEIRA, N. T. V.; BRAGA, M. F.; FALEIRO, F. G.; PEIXOTO, J. R.; BERNACCI, L. C. Potencial de espécies silvestres de maracujazeiro como fonte de resistência a doenças. In: FALEIRO, F.G.; JUNQUEIRA, N.T.V.; BRAGA, M.F. Maracujá: germoplasma e melhoramento genético. Planaltina: Embrapa Cerrados, 2005. p.81-106

KANAZIN, V.; MAREK, L.F.; SHOEMAKER, R.C. Resistance genes analogs are conserved and clustered in soybean. Proceedings of the National Academy of Sciences USA, Washington, v.93, p.11746-11750, 1996

LEISTER, D.; BALLVORA, A.; SALAMINI, F.; GEBHARDT, C. A. A PCR-based approach for isolating pathogen resistance genes from potato with potential for wide application in plants. Nature Genetics, New York, v.14, p.421-429, 1996.

MELETTI, L. M. M.; BRUCKNER, C. H. Melhoramento genético. In: BRUCKNER, H.; PICANÇO, M. C. (Ed.). Maracujá: tecnologia de produção, pós-colheita, agroindústria, mercado. Porto Alegre: Cinco Continentes, 2001. p.345-385.
MENEZES, J. M. T.; OLIVEIRA, J. C.; RUGGIERO, C.; BANZATO, D. A. Avaliação da taxa de pegamento de enxertos de maracujá-amarelo sobre espécies tolerantes à "morte prematura de plantas". Científica, Jaboticabal, v. 22, p. 95-104, 1994.

MOHLER V.; KLAHRA.; WENZEL G.; SCHWARZ $\mathrm{G}$. A resistance gene analog useful for targeting disease resistance genes against different pathogens on group 1S chromosomes of barley, wheat and rye. Theoretical and Applied Genetics, Berlin, v.105, p. 364-368, 2002.

MUTLU, N.; MIKLAS, P.N.; COYNE, D.P. resistance gene analog polymorphism (RGAP) colocalize with disease resistance and QTL in common bean. Molecular Breeding, Dordrecht, v.17, p. 127-135, 2005.

NCBI. Disponível em: <http://www.ncbi.nih.gov> Acesso em: 17 ago. 2009.

OLIVEIRA, J. C.; NAKAMURA, K.; CENTURION, M. A. P. C.; RUGGIERO, C.; FERREIRA, F. R.; MAURO, A. O.; SACRAMENTO, C. K. Avaliação de passifloráceas quanto à morte prematura de plantas. In: CONGRESSO BRASILEIRO DE FRUTICULTURA, 3., 1994, Salvador. Anais... p. 827.

PAN, Q.; LIU, Y.; BUDAI-HADRIAN, O.; SELA, M.; CARMEL-GOREN, L.; ZAMIR, D.; FLUHR. Comparative genetics of nucleotide site-leucine rich repeat resistance gene homologues in the genomes of two dicotyledons: tomato and Arabidopsis. Genetics, Bethesda, v.155, p. 299-322, 2000.

PAULA, M. S. Diversidade genética e reação de Passiflora SP. A Meloidogyne incognita e a Meloidogyne javanica. Dissertação (Mestrado) - Universidade de Brasília, Brasília, 2006.

SANTOS FILHO, H. P.; SANTOS, C.C.F. Doenças causadas por fungos. In: SANTOS FILHO, H.P.; JUNQUEIRA, N.T.V. (Ed.). Frutas do Brasil: maracujá fitossanidade. Brasília: Embrapa Informação Tecnológica, 2003. p. 12-21

SHARMA, R.D.; JUNQUEIRA, N.T.V.; GOMES, A. C. Comportamento do Maracujá-doce (P.alata) relacionado com nematoides formadores de galha. Nematologia Brasileira, Campinas, v.28, p. 97100. 2004. 
SOUZA, M.A.F. Avaliação de produtividade, incidência e severidade de doenças em frutos de 17 genótipos de maracujazeiro-amarelo, cultivados no Distrito Federal. 2005. 120 f. Dissertação (Mestrado) - Faculdade de Agronomia e Medicina Veterinária, Universidade de Brasília, Brasília, 2005.

STASKAWICS, B.J.; AUSUBEL, F.M.; BAKER, B.J.; JONES, J.D.G. Molecular genetics of plantdisease resistance. Science, Washington, v.268, p. 661-667, 1995.

STATSOFT. Statistics for windows: computer program manual. Tulsa, OK: StatSoft, 1999.

TAN, H.; ZHANG, X.; KARACA, M.; SAHA, S.; JENKINS, J.; CREECH, R.; MA, D. Isolation of resistance gene analogs in cotton (Gossypium Hirsutum L.) based on conserved domains of plant disease resistance genes. Euphytica, Dordrecht, v.134, p.1-7, 2003.
TULLU, A.; TAR'AN, B.; BREITKREUTZ, C.; BUCHWALDT, L.; BANNIZA, S.; WARKENTIN, T.D.;VANDENBERG, A. A quantitative-trait locus for resistance to ascochyta blight (Ascochyta lentis) map close to a gene for resistance to anthracnose (Colletotrichum truncatum) in lentil. Canadian Journal of Plant Pathology, Guelph, v.28, p.588595.2006 .

TUSKAN, G.A. et al. The genome of black cottonwood, Populus trichocarpa (Torr. \& Gray). Science, Washington, v.313, p. 1596-1604, 2006.

VALÊNCIO, A.G.R.B. Identificação de polimorfismo entre cultivares de cebola por meio de marcadores moleculares do tipo 'RGAs' (Resistance Genes Analogs). 2005. 112 f. Dissertação (Mestrado) - Faculdade de Agronomia e Medicina Veterinária, Universidade de Brasília, Brasília, 2005.

YU, Y.G.; BUSS, G.R.; SAGHAI-MAROOF, M.A. Isolation of a superfamily of candidate diseaseresistance genes in soybean based on a conserved nucleotide-binding site. Proceedings of the National Academy of Sciences USA, Washington, v.93, p.11751-11756, 1996. 